\title{
Vocational education in practice: a study of work-based learning in a construction programme at a Swedish upper secondary school
}

Magnus Fjellström

\author{
Correspondence: magnus. \\ fjellstrom@edusci.umu.se \\ Department of Applied Educational \\ Science, Umeå University, Umeå \\ SE-901 87, Sweden
}

\begin{abstract}
Background: In many OECD countries an apparent connection is shown between education, the local economy and the local labor market. This connection seems to be stronger and more radical in Sweden, than in other similar countries. The construction program is thereby also a part of this market. Given the needs of the building industry for competent workers and the requirements from specific course syllabuses this paper explores how project-based vocational education contributes to the student's vocational competences. The aim of this study was to describe and analyse students' perceptions of vocational competence gained from a PBVE environment and identify how this competence is constituted. From this broad aim, the following research questions were asked: (1) What kinds of competence are the students able to develop in a PBLE? (2) In what ways do the developed competence and vocational skills relate to the specific course syllabuses? (3) How is the students' vocational competence constituted?
\end{abstract}

Methods: Methods adopted for this study are observations over student action in a project based vocational education and focus group interviews with observed students.

Results: The result indicates a gap between acquired vocational competence at the project and the related learning goals in the course syllabuses. The developed vocational competence seems more adopted to fit the demands of the building industry rather than the intended course goals. Further, the findings indicate that the relationship between learning and support from teachers are strong whereas the room for individual initiative in the learning environment is limited.

Conclusions: This study highlights the relationship between student action and the complexity in vocational education as a project based vocational education. The project's high complexity affects the students' learning ability to take own decisions in the learning environment. This also affects the students' motivation and ability to develop competences required to fulfill goals in course syllabuses. So, if the students' are supposed to be able to be a part of their own learning the complexity in the task should not be too high. Hence, if the task is to easy the students' will not be challenge enough in order to develop vocational competences.

Keywords: Project-based vocational education; Learning environment; Vocational competence; Teacher guidance

\section{Springer}

C 2014 Fjellström; licensee Springer. This is an Open Access article distributed under the terms of the Creative Commons Attribution License (http://creativecommons.org/licenses/by/2.0), which permits unrestricted use, distribution, and reproduction in any medium, provided the original work is properly cited. 


\section{Background}

A connection between education, economy, and market has been shown to exist in many OECD countries. This connection is stronger and in many ways more radical in Sweden (Vetenskapsrådet 2011). The local government has increased demands on public upper secondary schools to enrol more students. To gain a higher share of the students, the construction programme in this study increased the number of its students from 48 to 64 students per year. This phenomenon of struggling to attract a higher share of the students in upper secondary schools is a result of increasing competition over the students. An important factor in this is the opening of the school market to private actors, in the form of 'free schools' that compete with the community schools for students (Arreman and Holm 2011).

Since 2006, project-based vocational education (PBVE) has been a component of this construction programme. As a result of having more students, the main part of the vocational education in this construction programme had to be outsourced to a worksite that is located away from the actual school. Because of the increased number of students, the students in years two and three are now building houses as a part of their vocational education.

\section{Learning environment}

In Sweden the three-year vocational education is school based, except for a minimum of 15 weeks of mandatory practice at a company. Nearly a third of the educational time is allocated to subject education. This means that more than half of the students' vocational education is carried out within a school context. In the first year they are located at the school premises. There they go through several mandatory courses consisting of both practical and theoretical aspects. After their first year the students enter the PBVE portion of the training, for the remaining two years. The school-based worksite is designed to look and function like a 'real' worksite with a site manager who runs the place, and vocational teachers who can focus on the students' vocational education. It consists of three almost identical houses and a large training ground with an area of approximately 200 by 100 metres. The students' vocational competence is thereby mainly based on the PBVE and the producing of houses that will meet the future demands. Based on the time frame from earlier house projects that the school has built, the expected time to produce these houses is approximate three to four years. Consequently, the students in this study will participate for about half the time that it takes to build these houses. In relation to previous projects, this project has been further developed by the school. The students are now building highly advanced houses that are expected to meet future demands for energy efficiency as well as meeting environment goals for the future.

The projects in this study were started one and a half year ago, with students who graduated in spring 2012. The students in this study started their PBVE at the point were the graduated students left off. The students therefore did not been participate in the beginning of this project. Considering the time frame for building these houses, they will probably not be there when the houses are finished.

However, this is not a problem or solution exclusive to the specific school. Government documents show that as early as the 1970s schools were encouraged to perform different projects to conduct their vocational education as a part of the construction programme (SOU 1970:58). Despite this being a common way to deliver vocational 
education in a construction programme, few studies in Sweden have been conducted that consider the development of students' vocational competence (Berglund 2009). On the other hand, research in other countries has shown that vocational competence is a complex phenomenon that is very specific to national demands (Winther and Achtenhagen 2009). The conduct and practices of PBVE are thereby ongoing processes in Sweden that have not yet been studied enough by researchers to determine what the students can learn from the structure of a project-based learning environment (PBLE). On the basis of the little research available and the fact that PBVE is a common way of conducting vocational education in the Swedish national construction programmes, it is important to shine some light on how this educational design can affect learning outcomes. To understand the relationship between PBVE and learning outcomes, this study highlights the views of students who are participating in this kind of learning environment.

The aim of this study is to describe and analyse students' perceptions of vocational competence gained from a PBVE environment and identify how this competence is constituted. From this broad aim, the following research questions were asked: (1) What kinds of competence are the students able to develop in a PBLE? (2) In what ways do the developed competence and vocational skills relate to the specific course syllabuses? (3) How is the students' vocational competence constituted?

\section{Theoretical framework}

Based on the context and aim of the study, aspects of activity theory were chosen to gain a higher understanding of the object under study. According to Berglund (2009), the basic assumption in activity theory is that individuals are formed as persons situated within particular contexts and in continuous interaction with their social environment they form their identities. From this point of view the students who are involved in PBVE are formed by and within that context. Based on Vygotskij's (1978) thoughts on the zone of proximal development (ZPD), parallels might be drawn to PBVE. The context of the project itself provides a field of 'scaffolding' possibilities for what the students can learn and achieve, while the teacher's didactic knowledge in interaction with the students' efforts and personal capacities shapes what vocational competence they can eventually develop. Based on the interplay between the construction and the educational context, and the role of participants as active and social learners, PBVE can affect the development within the students' ZPD.

With this understanding of learning as situated within contexts, the interactions between the teacher and the learner are important. Valsiner (2000) described the relationship as follows: "the person's development is being constructed in that 'zone' ... These 'half-ready' functions are both the target for the person's own efforts at their full information, as well as those for any kind of social intervention efforts" (p. 43). This includes the role of the teacher, as the one who interacts with the students to increase the students' understanding and vocational competence. The context, in interaction with the student's potential vocational development and the teacher's competence, thereby represents the potential of PBVE. The project's potential for technical and theoretical competence can contain flexibility or levels of freedom in the learning situation. High flexibility can provide possibilities for creative and 'high' learning, while lower flexibility usually promotes a reproductive or 'lower' learning (Ellström 1996). 
Following Ellström's view on learning and Vygotskij's (1978) theory of ZPD, the project's context and complexity, in combination with the expertise, talent, knowledge, and dispositions that individual participants bring to it, are crucial for the student's ability to develop vocational competence. This complexity was emphasised by Vygotskij (1978), who understood that children's development cannot simply be derived from the structure of the ZPD. Instead, he points out that "development in children never follows school learning the way a shadow follows the object that casts it" (p. 91). This points to the complexity of doing research on individuals and the problem of using models as a tool for analysing development. Understanding knowledge therefore involves interpretation and qualitative analysis. Leontiev (1978) brought another dimension to this discussion when he argued that the goal of action is also dependent on the motive for action. In that way the motivation to act seems to be a key part of education that makes the development of learning and acquisition of competence possible. Activities are always dependent on relations and motives. The motive can be seen in forms of realisation of an object, which consist of both physical and mental aspects (Leontiev 1978).

\section{Competence}

All education in the Swedish upper secondary school is based on a national curriculum. The students in this study are the last group that follows the 1994 curriculum for the noncompulsory school system (Lpf 1994). In Lpf 1994 four different elements are stated to define expected learning outcomes, namely: facts, understanding, skills, and accumulated experience. This approach to competence gives no clear answer to what competence is, but these four interacting elements are the foundation to understanding learning outcomes. Hence, the curriculum does not state a clear definition of the expected student learning outcomes, other than the four elements. Instead, there are definitions of expected goals related to competence that are stated in different course syllabuses. The concept of competence is thereby displayed in various government documents. As described in SOU (2001:78), competence is divided into professional, basic, and general competence. Professional competence is defined in following way: "Professional competence should reflect over the individual's ability to apply knowledge and use skills in specific tasks ... relevant to the profession". (p. 57). Basic skills include the Swedish language, both written and verbal; mathematics; and the basic use of a computer. General skills include: "... e.g. collaboration, quality and environmental awareness, the ability to organize work, problem solving, i.e. issues that industries seems to value and demand" (p. 58). This approach to competence gives no clear understanding of the concept of competence. Instead, the interaction between these elements is used to understand the potential development of competence.

On the other hand, Ellström (1992) described competence as follows:

With competence referred to [as] an individual's potential to act in relation to a certain task, situation or context. Specifically, the ability to successfully (according to their own and others' criteria) do a job, including the ability to identify, exploit, and, if possible, extend the interpretation, action and evaluation opportunities that the job is offering (p. 21).

Using these definitions in this study, an overall interpretation of competence can be seen in the situated context. This is highlighted by Winther and Achtenhagen (2009): "Actions and activities in the field of VET are very specific - not only with regard to the national scope of occupations but also regarding the differences between different countries an occupations themself" (p. 90). As these different approaches to competence 
indicate, understanding the definition of competence is highly complex, and therefore it has to be situated within the context.

\section{Methods}

This is a case study of students' development of vocational competence within a projectbased learning environment, and the connections between course structures and onsite learning. The site selected for this study is an upper secondary school in Sweden. The school is one of the largest in Sweden, and the construction programme itself has about 200 students, divided into three grades. The focus in this study has been on a third and final year construction class conducting their PBVE. This particular school and programme claim to be the most modern construction programme in Sweden. Due to their work within VET and the structure in this modern learning environment, it is important to shine some light on how the instructional design might affect students' learning outcomes. The methods adopted for this research are based on observations conducted in a PBLE and focus group interviews with the observed students.

The methods in this study are inspired by Atkinson and Hammersley's (2007) thoughts of how to conduct field research. According to their view, observations and interviews are forms of data collection appropriate for researching real context environments, as in this case, a PBLE. The empirical material stems from eleven full-day observations and four group interviews with students, which were each between 65 and 80 minutes long. The data from the observations consists of about 90 hours of onsite observations that were recorded by taking field notes. The observations were carried out in the space of two month in autumn 2012 and one month in the beginning of 2013. Observations of the teachers and site manager were done simultaneously, to further understand the relationship between the project's complex structure and the students' potential learning outcomes.

The focus group interviews are inspired by Kvale and Brinkmann (2009) approach to conducting a qualitative interview and by Merriam (1988) guidelines for performing a case study, as it is the most appropriate way of seeing this study. The semistructured interviews were made according to Bogdan and Biklen (2007) thoughts on getting data that are comparable between subjects. They were done to capture the students' experiences according to the observed actions, as well as to identify both the teachers' and the students' support and guidance for opening up the scope of learning. The choice of focus group interviews is grounded in Cohen et al. (2007) idea that group interviews can generate a greater response to the research object and that the students discussions can enrich the description of a phenomenon. Cohen et al. (2007) put it like this: "It is from the interaction of the group that the data emerge. Focus groups are contrived settings, bringing together a specifically chosen sector of the population to discuss a particular given theme or topic, where the interaction with the group leads to data and outcomes" (p. 376).

\section{Data collection}

The first day of observation can best be explained as a low structured observation, where field notes were taken at all three houses. These field notes came out as an open structured observation of everyday action regarding the practical vocational education at the project. As Atkinson and Hammersley (2007) declared: "Fieldnotes are always 
selective: it is not possible to capture everything" (p. 142). This study also deals with the concern that not everything that is observed can be captured in writing. This is defined by Wolfinger (2002) as the relevance of what one can see being based on the researcher's sense of what is expected to be seen. My selection is based on the analysis of the first observation, which that resulted in the development of an observation matrix. The matrix consisted of four categories: observations, questions, own thoughts, and other. The field notes were assigned to the most suitable of these four categories. This matrix was used for the subsequent observations' under the following observations.

As a model for initiating the interviews, the field notes were organised into six themes (see a further explanation in the constitution of vocational competence), each of which characterised something that had been observed, sometimes for several weeks, and that the students had experienced. These field note-based interviews were structured into sections within each theme, where the students after each section got the opportunity to discuss what I had just read for them. In themes 1-5 there was always something that overturned their first argument, and they thereby had to reconsider their standpoint and discuss in what way their vocational competence was constituted. Theme 6 refers to one phenomenon that was displayed during one day of the observations. These semistructured interviews were influenced by a stimulated recall approach to engage the students in the discussions of the themes. A central part in stimulated recall is that the researcher stimulates the informant by displaying something that triggers the informant to discuss an occurrence (Alexandersson 1994). According to Haglund (2003), stimulated recall can be structured in many ways, as long its intention is to trigger the informant to participate in the discussion. Different types of data are thereby used in this study to capture and understand the students' agency of learning, as well as to identify the vocational competence that can emerge within the frame of PBVE.

\section{Methodical considerations}

The data collected by this approach contain both limitations and benefits to the study. The data that were obtained in the observation study consist of both a generous amount and depth of data that have made the observed object more understandable. The first observation, which was an unstructured observation with an open-eye approach, made it clear how the upcoming observations would be conducted and what I would observe. This ended up in the development of an observation matrix, which made the field notes more structured. With the guidance of this matrix, the observations could be categorised according to the activities the students were performing at the project. The development of the matrix also helped me to categorise the field notes, so they could more easily be compared with the goals in the course syllabuses. The development of the matrix thereby helped me to categorise and structure the field notes into understandable and analysable sentences. I am aware that this matrix also made me blind to other aspects of what I have could observe or take field notes about. As well, as field notes always are selective selected, according to Atkinson and Hammersley (2007), these field notes clearly show the ongoing process of building these houses. The field notes captured the core of what was supposed to be seen, according to Wolfinger's (2002) notion that field notes should capture relevant data.

By using field notes from my own observations as a guideline in the interviews, I encouraged the informants to discuss observed student actions. Thereby, aspects that was 
not observed, or about which field notes were not taken, were probably not discussed in the interviews. By this limitation, aspects that might have been overlooked by using field notes as a guide to the interviews can reduce the informants' 'freedom' in the interviews. This eventual loss of data might have been reduced if the observations had been videotaped and shown to the students.

\section{Data analyses}

The analysis of the observation data was conducted in multiple stages. The first step was an analysis of the course syllabuses that are connected to the vocational education at the project. This analysis broke down the goals in the course syllabuses into concretely observable goals of practical know-how. This step was central to the upcoming analysis in order to assign the field notes to suitable categories. This allowed me to focus on the observable know-how goals. The second step in the analysis considered the transforming of field notes into understandable meanings by adding complementary words to the sentences. The detected tasks in the field notes were categorised into the most suitable goals in the course syllabuses by placing them in a matrix that enabled me to compare the field notes with goals displayed in course syllabuses. The analysis of course syllabuses detected a total of 108 goals. These were divided into 53 know-how goals and 55 know-what goals. Based on what could be seen through observations, this study focused on the observable practical know-how goals. Thereby, patterns of what the students are doing when they are conducting their PBVE were detected. From this stage the data were transformed into understandable knowledge of the relationship between goals in course syllabuses and potential competence gained from this PBVE.

To further understand the students' learning outcomes, focus has been on what they actually 'do' rather than what they are not doing. Accordingly, the analysis of the interviews concerned how the students think and reason about their own learning. The analysis of the transcribed interviews consisted of structuring the data into the different phenomena displayed in the different themes, following Kvale and Brinkmann (2009) ideas about how an analysis of interviews can be structured. This allowed an overview of the data from each interview, which made the material easier to organize and compare. By comparing the transcribed interviews between the focus groups, students' thoughts about their learning emerged from the data.

\section{Results and discussion}

This study focused on describing and analysing development of vocational competence gained in a project-based vocational education, and the experiences of learning reported by students participating in such projects. These are presented under the headings The complexity impact, project-based vocational competence, and the constitution of vocational competence.

\section{The complexity impact}

The vocational competence gained by students within this PBLE depends on what they are enabled to do within the framework of the project. This highlights the problems that emerge in practice, when complex coordination is needed between the architectural plans for the construction, the site manager, the teachers, and the students. Both the complex nature of the task, and the multiple viewpoints that are expressed by 
participants with different expertise, can produce confusion and lack of clarity for the students as well as a lower level of involvement by students in some of the activities.

Despite the amount of work and the potential ability to reach vocational competence within the project, the observations show that the students have low motivation to engage in upcoming tasks, as a result of not only task complexity but also poor coordination between involved. A common strategy among the students seems to be to fall into inactivity to avoid making mistakes. This phenomenon could be related to the interaction between students and their teachers. When a student decides to proceed with a new activity, a teacher or a site manager usually intervenes in the student's action to avoid things being done wrong. This process seems grounded in both the complexity of the construction process and problems of transferring the drawings of the building into the 'messy' reality of the construction site. In relation to the drawing problems, the involvement of the architect plays a crucial role. The architect's thoughts on how the building should look and function affect the decision process between teachers and site manager regarding how something should be done.

The consequences of these complexities and the frequent interventions by the teachers and site manager in the students' work lead to slow progress in the building process. For example, one student had moved a wall three times before the teacher and site manager determined where the wall should be placed. In this example, the teacher and the site manager discussed the placement of the wall without consultation between the teacher/ site manager and the students'. The result was that both the teacher and site manager tried to affect the outcome of where the wall should be placed. Interestingly, in this example, the architect's drawings showing where the wall should be placed were not initially used, although the final placement of the wall was according to the drawing. This problem of transferring the drawing into reality was often expressed as poor communication between the teacher and the site manager, which resulted in passivity among the students.

This kind of struggle between the various parties involved shows how the complexity of these houses creates insecurity between the teacher and the site manager concerning how they should be built. A statement from a student shows how this struggle affects the students' performance and motivation. In responding to my question, 'Why did it go wrong?', one student answered, “The teacher said it was correct last week, but now he has changed" ... "and yet he was with us and did one himself". This is an example of how the students, with the teacher's help, did something that next week is supposed to be done in a different way. This practice of redoing already existing things was observed several times. The students' motivation to search for solutions to specific problems was reduced, given the high chance of their work having to be redone. Despite the general noted lack of motivation, some of the students were trying to be active and progress. During the observations, these students were stopped by either the teacher or the site manager, who referred to the architect to solve upcoming problems. The students' reaction was that of frustration. It seems that the students' willingness to try to move forward was stopped, because no one knew how it was supposed to be done or because they lacked the materials for the task. Despite the drawings, there seems to be a constant discussion on how things should be done between teachers and site manager, while the students are passive observers. The transforming of the drawings into reality is something that the students are not in practice involved in, even though they have access to the drawings. 
Project-based vocational competence - incomplete tasks and skills?

Even though the syllabuses prescribe a significant number of goals and skills, the findings suggest that a number of these skills are not acquired by the students during their participation in the project. At the same time, this study shows that students develop other kinds of competence that are not necessarily reflected within the course syllabuses. So, there are differences between the types of competence stated by the course syllabuses and what the students actually are able to learn from this project. For the purposes of reporting the findings below, the stated areas of competence are divided into course-based goals and complementary competence.

\section{Course-based goals}

The students' activities on practical know-how goals are seen through mainly the courses on 'cladding' and 'building insulation'. In addition to these, the courses 'framing' and 'repair and renovation' were represented. The observations identified a total of 45 tasks performed when the students were practicing course-related exercises. From the 45 observed tasks, 25 were related to the cladding course and more specifically to the goal of, in practice, being able to handle different types of cladding. The second most detected tasks were on building insulation, where 12 tasks were observed. These tasks can be divided into the following goals: (1) to be able to carry out work with thermal insulation, and (2) to be able to assess and discuss how the work corresponds to specific national regulations. The courses framing, and repair and renovation, were represented four times each. Thus, the main tasks observed were in the area of cladding.

On the basis of goals detected in course syllabuses, the main observed task consisted of developing practical cladding competence. Overall, this study detected a total of 12 different areas of competence that the students were able to develop through this practical vocational education. The findings indicate that the students could not reach all of those 53 know-how goals that are related to the course syllabuses. This is related to both the outsourcing of different tasks such as mounting windows, thermal insulation of outer walls, and roofing, and to the project having been started 18 months earlier by other students. Practical vocational competence that follows these tasks was thereby impossible for these students to develop through this project. It is notable that during the observations, 47 tasks were observed that could not be related to any of the seven course syllabuses connected to the students' time at the project.

\section{Complementary competences}

The observations detected several tasks that cannot be related to any of the practical aspects in the course syllabuses. These 47 tasks consist of instructions and tasks that the teacher or the site manager think are important for the students to develop competence in. These important tasks are often portrayed as common sense regarding the way someone should act on a construction site (i.e. the demands from the building industry). Complementary competence that the students are developing through the project seems to be related to the complexity and structure in these houses with very high energy efficiency. Several of the observed tasks could therefore only be related to the specific project. In each observed task of solving a construction problem, the teacher, the site manager, and/or the architect was involved. The students were at all observed times 
passive observers in that process. In most instances, this was experienced and talked about as frustration over not having anything to do. On the basis of many non-course related tasks, it indicates that this building provides areas of competence that are not stated in course syllabuses. Instead, they follow the specific project.

\section{The constitution of vocational competence}

The interviews are organised here according to the same structure and themes as presented to the students. Each theme contains a phenomenon that will be explained in brief, followed by the most central core content. The interviews are grounded in my observations of the students' actions and based on the field notes taken during the observation phase. The third-year students followed were at their PBVE two days a week, as were the second-students, but on different days. Because they are at the same project, some development in the building progress could have been done when the students in this study were not there.

\section{Theme 1}

Engaging in a task This theme demonstrates how one student with knowledge in a particular construction task is trying to engage another student and thereby act as tutor to that student. This peer-tutoring model, although with great potential for sharing learning experiences, proved often to be problematic. In the example below, the critical elements missing from the interaction were to do with the lack of definition of tasks, but also lack of endorsement of the exercise by one of the teachers.

The student explains correctly the upcoming task to the other student, but he chooses to take a passive approach to the task by saying that he does not know how to do. One major issue for the students was that the exercise was not organised by the teacher. The students express insecurity about engaging in a task that was not initiated by a teacher, because it could result in having to redo the assignment. Therefore, it seems logical for the students to avoid taking action, to ensure they will not do anything wrong. This insecurity seems to be grounded in the students having done a lot of redoing of assignments, which my observations showed. Another explanation that frequently was offered by the students concerned the issue of motivation. Because the task was not initiated by the teacher, it was seen as optional. The students' willingness to take on a new task is thereby reduced, if the teachers do not firmly take control of planning the learning experiences.

Later on, in this particular example, the teacher explains to the student how to engage in the task, and only then does the student begin. After a while, and despite the initial direction, the student begins to see that it is going to be wrong. Instead of rethinking the situation, he continues with the assignment. Eventually the student contacts the teacher to report the emerging problem, trying to understand what was not done correctly.

During the interviews several of the students discussed similar experiences, where contact with the teacher should have taken place earlier in the process. Delaying seeking help often meant that assignments had to be redone. But, other than students taking initiative to ask for feedback, some of the students also reported contradictory advice given by teachers on specific tasks. At the same time there were students who said that they often redid tasks over and over, because different teachers were saying 
different things. From the students' point of view, some of the teachers are more skilled than others in engaging them in a task.

This theme shows how important the relationship between student development and teacher-driven learning support is, in terms not only of completing tasks and avoiding mistakes but also of building motivation and confidence. The potential for learning from student peer-learning situations is lost when there is not an adequate support structure provided by the teachers, since the power of expertise and professional skill that teachers are seen to have is paramount in students' perceptions. In the particular example described above, having followed the instructions of his peer, the student would have completed the task correctly, if he had had the confidence to rely on his peer's advice. Hence, the students' perception is that the teacher's instruction is the most valuable part when they are engaging in a new task, but if they have done a similar task before, they expressed wider room for own solutions. This seems to be grounded in their personal development of vocational competence that enables creative solutions based on their increasing experience of their vocation.

\section{Theme 2}

Redoing assignments This theme illustrates the significance of teacher-structured learning environments for (a) the completion of tasks, (b) retaining a high motivation and engagement by students, and (c) ensuring a collaborative environment where there is high degree of trust by the students.

In this example, a teacher gives an instruction to a student who is asked to redo an assignment on interior wall cladding. The teacher informs the student that the existing mounted plywood has to be removed; otherwise the hallway will be too narrow. There should only be mounted a gypsum wallboard on the wall. The student's motivation seems low, and as the student gets on with the task, more problems begin to emerge. It seems that the plywood was mounted there to hold back an electrical device, which now had to be reinstalled in another way. As the teacher comes by, he notes that the joist closest to the doorframe is bent and has to be replaced, which the student is instructed to do. This redoing assignment that started by taking down one plywood board ended up taking one whole day, including all the other tasks that followed. The students expressed their dissatisfaction at the time it took to carry out that assignment, but they also accepted during the interview that their low motivation could have been, at least partly, the cause of it. In their discussions the students perceived such redoing of assignments as meaningless for their development of vocational competence. However, this form of redoing assignment shows how the student's vocational skills were put to a test. The problem-solving situation that accrued had to be solved, and so it was.

Further on, when the students are back after the weekend, they all notice that the second-year students have put up plywood on almost all the walls and continued to mount gypsum wallboard on top of it. The third-year students now start to work where the second-year students left off. When the teacher comes by, he seems to accept that the walls are covered with plywood and instructs the students on how to move on. This is the same wall that last week took a student a whole day to redo, and now it seems as if their earlier work did not matter. The student's reflections over this phenomenon were quite insignificant. They reported that teachers often do not communicate with 
each other, resulting in such unproductive and repetitive tasks for the students, which do not contribute to their learning outcome. The teachers' non-communication or 'dysfunctional' way of talking to each other also affects the student's motivation in a negative way. They students also display insecurity in engaging in a new task, in anticipation of having to redo assignments several times during their work at the project. Some of the students even saw a distinction between the different teachers' ways of engaging the students in a task. One student describes it as follows: "Some teachers give more correct instructions and are therefore more trustworthy. With some of the teachers we always have to redo things". The students often referred to the drawings at the same time as they said that they never used them. So, they identified as problematic the fact that the architect's designs were not systematically integrated into their own plans and into their teacher's instructions, and they linked this causally to the frequency of failing tasks that then needed to be redone. None of the students seemed to have an explanation as to why they or their teachers did not use them, despite their knowledge about the high frequency of redoing assignments, caused by bad communication.

This theme demonstrates how the students redid an assignment that in the end did not have to be redone. The teacher's communication with each other seems to be a key issue, and at the same time the use of drawings appears to be low, among the students as well as the teachers. The teachers' own experience in construction work seems to be central to their transforming of the drawings into a student task. Despite didactic competence among the teachers, the students' willingness to engage in a task seems to be affected by the experience of frequently being assigned to unnecessary redoing assignments.

\section{Theme 3}

Engaging in a problem-solving task This theme illustrates the significance of (a) early intervention and guidance of students in their engagement in problem-solving tasks, and (b) the students' active engagement in the deliberations for finding solutions to emerging problems. The first example here shows a successful learning situation where an early and guided intervention by the teacher has helped the student to understand the nature of the difficulties he was facing in a particular task.

As a student tries to perform a task consisting of mounting gypsum wallboard in a bathroom near a window, he encounters some difficulties. The student wants a teacher to look into the problem before he continues with the task. The teacher explains how the task should be done and offers to show him in another bathroom how it should look when it is finished. This introduction to how the student can solve the task is highly appreciated by the students. They understand that it is easier to perform a task if they can see in advance the expected result. With respect to the teacher's willingness to show how it is supposed to look like, some students point out that it will only show the finished result and not how the task is accomplished. Instead, they want to be helped and instructed near the actual problem, as they see that every problem has its own specific solution, and to see the finished result does not help them to solve the underlying difficulties. The students emphasise that problem-solving activities should be led by a teacher, because teachers are more skilled and they should thereby be the ones who take initiative in the problem-solving activity. But, in the same example, I observed a less positive set of interactions that resulted in the student choosing to leave 
the learning setting, because he was not actively involved in the problem-solving situation. As noticed, a setting that could have provided an excellent opportunity for the student to take part in a problem-solving discussion with his two teachers ended up with a certain degree of disillusionment and the student's decision to remove himself.

The student and the teacher enter the finished bathroom to look at what had been done. The teacher immediately identifies what is wrong. Then another teacher enters the room, and the two teachers begin to discuss how they should solve the problem. The student who had asked for help is not involved in the conversation and walks away, thus missing the problem-solving discussion that has now developed into a teacher-teacher communication. Overall, the other students seem to agree that the student should not have gone away. But on the other hand they understand the reaction from the student. They have all experienced similar situations where problem-solving became a teacher-to-teacher interaction and where they felt excluded from the discussions. Hence, the majority of the students say that this kind of participation is important for their development of vocational competence, due to problem-solving activities being a good learning situation. On the other hand, the students are clear that they want to participate and that they want the teachers to evaluate but also to value their comments, acknowledging, of course, at the same time that they cannot be the ones that take the responsibility for the final decision for construction solutions.

This theme displays the problem-solving situation as a teacher-centred activity, despite the student's eagerness to participate in such situations. As the students were clear that they did not want to be the ones who take the decision, they felt that it was a good learning opportunity. As to the problem-solving activities themselves, students emphasised that minor problems can offer the opportunities for a student or student-student problem-solving activity, as well as students actively participating in selecting between different solutions that the teachers offer.

\section{Theme 4}

Trust in teachers' professional competence and behaviour This theme illustrates the importance of vocational skills that the teachers need to have and to demonstrate for the students. In the example that follows, there is a certain level of distrust that students show in the level of competence and expertise that teachers occasionally display. Even if these are not often occurring events, a show of lack of competence by a teacher (as perceived by the students) is enough to shake the faith in the learning environment and the teacher-learning relationship. This is further exasperated if the teachers do not follow such situations with sessions where the problematic is presented and the decisions are taken away, i.e. the students are relieved of the decision making responsibility.

The students are redoing all window openings that they have done. The irritation level is high and one student comments on the situation: "The teacher said it was okay last week and now he has changed his mind. He was with us and did one by himself and still it was wrong". According to the students, this is not an isolated incident. It is actually a very common phenomenon to redo the tasks because teachers have given contradictory or wrong information. The students believed that it was the constant changes in the drawings, grounded in the complex structure of the specific project, which affected the teachers 'disinformation' to the students. On the other hand, they also saw the teachers' constant changing of instructions as a lack of vocational 
competence. The students often attributed their apparently low motivation to these redoing phenomena.

Some students expressed that they had developed a strategy to prevent these large scale redoing tasks by working at a slow speed so they did not have to redo so much. An important issue is that the not one of the students had done these openings by looking at the drawing. One student said, "I think I have seen a drawing somewhere ... but we do not need it, because we know the measurement". This shows the relationship between the teacher and the students. Despite what the drawings say, the teacher's word seems to override the drawings. At the same time, the students value the drawings highly, because they indicate how something should be done. When it comes to the performance of a task, this aspect appears to be overlooked by the students. Instead they refer to the possibility that the drawings might be changed or that reality does not match the drawing. Therefore, the teacher's words are more important to follow than the drawings.

This shows the complexity in PBVE that is grounded in this 'experimental' way of constructing a building. The vocational competence of the teachers is a key issue when the transforming of the drawings must match the reality. The teacher's didactic skills can also be seen as a powerful source to increase the student's motivation by reducing the redoing of tasks. Based on the students' willingness to learn their vocations, it seems as if the students' eagerness to learn is reduced if they have too many redoing assignments. However, the students also refer to some of the redoing tasks as good learning situations that never occur at a real worksite. So, depending on the aim of the redoing task, some efforts are apparent.

\section{Theme 5}

The consequences of disinformation and interruptions To engage the students in a new task, the teacher informs the student before they go outside. The students are instructed to go two by two and to follow a company that is mounting windows. The teacher explains how to do the task and what to think about. The teacher even explains that he will give the students a practical introduction at house no 1 later on. This start is highly appreciated by the students. They remark this instruction as a perfect one and point out that it is important that the teacher transform his instruction to reality by a hands-on demonstration showing how to do the task. This is very important, especially when there are new tasks. The students point out how this kind of instruction increases the efficiency of the students, because when they go outside they already know what to do.

When the students, after watching a well-performed instruction, get to the house, they quit early, as they realise that all of the windows are already mounted. The teacher's practical introduction regarding mounting windows is thereby rendered impossible. The practical introduction at house no 1 is instead conducted at house no 2, and comprisesd another task. The teacher now starts to introduce the students to the job of taping joints to achieve a vapour barrier between the window and the wall. $\mathrm{He}$ also informs the students that if they do not get it correct they will not pass the window course. (There is no window course. My note.) The students' reaction to this is unitary. They all expressed how typical this was and that this kind of phenomenon affects motivation. They all looked forward to mounting windows and it ended up in 
taping joints, which the students expressed as a boring assignment. As to the fact that all the windows were mounted, one student said, "Even a blind man could have seen that the windows were mounted".

After a while the site manager stops the work with taping joints and says that the architect is coming by to show them how the taping is supposed to be done. Note that the teacher already has instructed the students. This break takes a couple of hours, which results in the students lapsing into a passive mode. The architect arrives at the project when there are two hours left of the day. The first hour goes to discussing with the teachers and site manager how the taping should be done. This is followed by a practical instruction from the architect that lasts one hour. The students pay less and less notice to his instruction. After 45 minutes one student says, "But it is just taping" with which the architect agrees. So, this day that was supposed to start with mounting windows ends up with doing nothing. The students' reaction to this is frustration. The day started with a 'perfect' introduction, just to end up with doing nothing.

Several of the students expressed that they were concerned about having to redo everything that they had taped. The students also referred to taping being a boring assignment and commented that it never seemed to end. The teacher's ability to create a meaningful learning situation was also hampered by the interruption arising from the site manager's decision to have the architect act as an instructor. The architect demonstrated the same thing that the teacher had done earlier, which the students experienced as an unnecessary instruction that only decreased their motivation. The consequences of this arrangement were a decreased motivation among the students and nothing getting done that day.

\section{Theme 6}

Instead of following all students, the focus in this theme was on a small group of students located in one of the houses. As in the previous theme, the teacher instructs the whole class in a teaching barrack on how to perform a task. But here the teacher does not follow up with the students with a practical demonstration of how it is done. This results in the students seeming to wander around, apparently not knowing what to do. When the students arrive at the worksite they have to wait for one hour before the teacher shows up at the place where the task is supposed to be performed. In the meantime they are not doing anything useful. Their time is spent mainly playing on their cell phones. As the teacher arrives to instruct them verbally onsite, the students pay little attention to his instructions. The instructions take three minutes to deliver, whereupon the teacher leaves. The teacher's way of engaging the students in the task was questioned by the students. The students reflected on this phenomenon as something that happens when they do not know what to do. Some even said that it is easy to get away with doing nothing, because the teacher pays more attention to the students who show that they want to learn, which was obviously not the issue here. The students did question this behaviour, especially the ones that felt that they needed the most help.

The next visit from the teacher is three hour later, and the students are on their way to leave for the afternoon break. One student wonders if they have done it wrong. The teacher answers by saying, "I hope not. I trust that you have performed it correctly". The teacher is there six minutes, and then he walks away. Thus, even though the 
teacher has not given practical instruction to the students on how to perform the task, he argues that they should know how it is supposed to be performed. In this situation the students apparently are seeking confirmation for their performance, while the teacher takes it for granted. Despite the long time between the visits from the teacher and the students' obvious inability to perform the assigned task, the teacher perceives it as laziness from the students. The students argue that it is because they do not know what to do and the teacher never seems to be around so they can ask. The teacher comments that they can always look for him if there are any problems. The students all agree that it is possible, but that it very rarely happens. It is easier to just sit and wait for the teacher. In total the teacher was with these students for fifteen minutes of this day. The teacher's engagement with the task clearly affected the learning outcome for these students. Whether or not the teacher instructs the students verbally, it seems important that the task be demonstrated in a practical sense. The transformation of words and drawings into reality is thereby a key issue for the students' learning outcome.

\section{Conclusions}

This study shows how PBVE affects the students' ability to gain vocational competence. The most characteristic areas are the motivation that follows the complexity of the project and the vocational competence that the students are able to develop within the specific project. These areas are displayed in complexity, decision making and motivation, and the possibility of project-based vocational education. As a finishing point of view, the conclusion will address the scope of learning through PBVE.

\section{Complexity, decision making and motivation}

This study indicates that students are forced to redo many tasks that were already completed earlier, and that these redoing tasks lead to passivity, which seems to have an impact on motivation. According to the students, this ongoing redoing activity is holding back the progress of what a student can learn, and therefore, it can be seen as a key issue that restricts the development of vocational competence rather than enabling it. On the other hand, these redoing tasks can lead to an increased development of skills and accumulated experience in accordance with Lpf 1994. This is, however, not something that the students' expressed. Instead, they drew the conclusion that these redoing tasks affect their motivation and that they do not learn anything from them, except to work slowly. The students' reflection over these redoing tasks might be related to their own ability to affect the progress and the performance of a task.

The students' ability to engage in problem-solving activities is, however, often hampered, as they are held back by teachers or the site manager. According to Ellström (1996), such a degree of learning freedom can be placed at the lowest level of autonomy in learning, where students have no freedom in the learning situation, a reproductive learning. However, some students expressed that in easy tasks sometimes they can choose between different methods. If that is the situation, the students' learning can move towards a more productive learning.

The process of redoing tasks indicates insecurity or poor communication between the teacher and the site manager about how something should be done. That also 
affects the student's motivation in a negative direction. Despite many similarities, compared to an ordinary house the complexity of building these projects seems to affect the production time and thereby the possibility to develop vocational competence that follows the construction phase of the project. Assuming that this is probably the future way of building houses, it can be questioned whether there are any alternatives. What would happen if they were building ordinary houses that follow common solutions and building regulations? Could this result in vocational competence that no one will want in the future, and consequently, the student will not meet the upcoming demands from the building industry? The primary question might be whether it is better to educate for the present demands rather than upcoming ones.

As the findings of this study indicate, there seems to be an issue around decision making about how something should be done. This phenomenon seems to be grounded in the complexity of the houses, where constant problem-solving dilemmas arise along the production. With Vygotskij (1978) ideas about how ZPD is a part of students' development of learning, these problem-solving dilemmas reduce the students zone of potential development. One issue that affects the ability to gain vocational competence follows the problem-solving dilemmas that result in redoing tasks and the slow progress in the building process. This affect the opportunity to try new tasks and thereby the potential development of vocational competence. The students' ability to expand their ZPD is reduced. It can be discussed whether the frequency of redoing tasks and the ability to participate in more tasks is coherent with each other in this PBVE. Following Ellström's (1992) notion that competence is related to the ability to perform a job that is successfully performed, it could be questioned whether a redoing task that is redone because of changes from the site manager or architect can be interpreted as a successful job that enhances the development of vocational competences.

The relationship between problem-solving dilemmas that result in redoing tasks and the student's motivation for the assigned task is distinct. According to Leontiev (1978) the motivation for action is a key issue that will bring the knowledge forward. Motivation is related to the context, and as well, to developing vocational competences. The students' ability to participate in upcoming tasks is reduced by working on redoing assignment. These redoing tasks can, according to Ellström's (1996) view of learning, be displayed as a reproductive learning, which can be seen as the lowest level of learning. Based on many the redoing tasks and the problem-solving dilemmas performed by the teachers and site manager, it can be questioned whether the project is a good project, one that encourages the development of vocational competence. If this specific PBVE mainly provides the lowest level of learning, according to Ellström's view, it can also be questioned whether this PBVE is meeting the future demands of the building industry. However, if the structure of the problem-solving process were included more in the students' work, they could reach a higher level of learning by employing different methods to solve a task. That level of freedom seems to be missing in Ellström's model of students' freedom in the learning environment. If the students were able to participate or even on their own to do problem-solving activities, the learning level could be placed between method- and problem-controlled learning (Table 1). In response to the findings, this level of learning freedom can, I suggest, be called task and result controlled. This learning level is a productive learning with the freedom to chose a method with a given task and result. This level of learning can occur if the students are allowed 
Table 1 Generated learning level in project-based vocational education

\begin{tabular}{lccccc}
\hline & \multicolumn{4}{c}{ Types of learning } \\
\cline { 2 - 5 } & $\begin{array}{l}\text { Reproductive } \\
\text { learning }\end{array}$ & \multicolumn{3}{c}{ Productive learning } & Creative \\
\cline { 3 - 5 } $\begin{array}{l}\text { Aspects of } \\
\text { learning situation }\end{array}$ & Given & Given & Gethod & Task and result \\
controlled & $\begin{array}{c}\text { Problem } \\
\text { controlled }\end{array}$ & \\
\hline Task & Given & Given & Not given & Not given & Not given \\
Method & Given & Not given & Given & Not given & Not given \\
Result & & &
\end{tabular}

Developed from Ellström (1996) thoughts of freedom in various learning situations.

to make problem-solving decisions by themselves, or by being involed in the problemsolving dilemmas.

So, the students' learning can move from a reproductive learning to a more productive learning. An important question for this to occur is whether the students are able to solve a problem in interaction with the teachers or site manager. Considering the number of redoing tasks, it seems that it is not clarified who is responsible in this problem-solving process. If the students are supposed to be a part of the problemsolving process, it has to be clearer what kind of problems the students can or are allowed to solve.

\section{The possibility of project-based vocational education}

There are differences between the types of vocational competence gained from a PBVE and those indicated in course syllabuses. The specific project provides opportunities to gain vocational competence in areas that are closely connected to the phase of where the project is. The result is that the project is the steering part in PBVE, and the goals related to course syllabuses are overlooked. If that is the situation, the focus on producing these houses is greater than the students' need to gain vocational competence according to the goals in course syllabuses. Another issue is the outsourcing of different tasks. If the students are not able to do a task, they cannot develop that competence within the frame of this PBVE. However, if other structures and/or construction solutions in the building process were used, the students might be able to develop competence in the areas that follow those tasks. The students' vocational competence is thus adapted to the project, and the students are developing competence in areas that are related to the specific project.

Despite the vocational competence that is gained from the specific project or related to course syllabuses, the slow progress of building these houses seems to affect the students' learning outcome. The students are not learning what they might, if they had the opportunity to make better progress in their learning environment. According to Engeström (1987), object-oriented activities affect the result; consequently, this project will affect the development of vocational competence. These factors raise questions such as whether this kind of project is suitable for the student's vocational education. Or, is it better than the alternative? Maybe the potential of the project is more suited to providing the building industry with competent workers than to fulfilling goals in course syllabuses. If that is the case, then the course syllabuses do not fit the needs. If so, does this mean that the goals in the related course syllabuses have partly played out their role? If the potential vocational competence generated from this project is 
meeting the demands of the building industry, it has to be considered whether the course syllabuses are suitable for the demands of the work life.

\section{The scope of learning through PBVE}

The complex structure and constantly changing solutions are a key part in the students' development of vocational competence. With Vygotskij's thoughts of ZPD in mind, and the complex situation, the project itself reduces the teacher's ability to act as a master for the students. Due to constant changes in the construction, the teacher's vocational competence is put to the test. If the teacher's word today is wrong the next day, as these redoing phenomena indicate, then the teachers have lost their master status. Despite these phenomena, the teachers' engagement is highly valued by the students. That indicates that the teachers' power over the students is higher than the ability to act as a master. As Valsiner (2000) explains it, the students are a target of the situation. Besides the teachers' guidance and the projects' potential, the students' ability to act is reduced due to the experience of many redoing assignments. Even if a student can act, the force of knowing the action might be wrong overturns the student's ability to act. Therefore, the students won't expand their 'zone' by guidance from another student. The complexity of the situation can affect the students so much that they stop taking initiative in their own learning. The conclusion is that the complexity of a task cannot be too high, if the students are supposed to be a part of their own development within their ZPD. Whereas the room for individual initiative in the learning environment is limited, it could be questioned whether a single construction programme should be a part of an experimental building project that is so complex that the teacher's master status is overturned and the student's ability to act is reduced. The things the students are learning are probably meeting future demands, but the question is whether that can be motivated, due to several gaps in the student's opportunities to meet the current demands from the building industry.

Competing interests

The author declare that he has no competing interests.

Received: 24 September 2013 Accepted: 26 December 2013

Published: 24 January 2014

References

Alexandersson M (1994) Metod och medvetande. Acta Universitatis Gothoburgensis, Göteborg

Arreman IE, Holm AS (2011) Privatisation of public education? The emergence of independent upper secondary schools in Sweden. [Reports - evaluative]. J Educ Policy 26(2):225-243

Atkinson P, Hammersley M (2007) Ethnography: principles in practice, 3rd edition. Routledge, Milton Park, Abingdon, Oxon; New York

Berglund I (2009) Byggarbetsplatsen som skola - eller skolan som byggarbetsplats? [Elektronisk resurs] : en studie av byggnadsarbetares yrkesutbildning. Institutionen för didaktik och pedagogiskt arbete, Stockholms universitet, Stockholm

Bogdan R, Biklen SK (2007) Qualitative research for education: an introduction to theory and methods, 5th edition. Pearson A \& B, Boston, Mass

Cohen L, Manion L, Morrison K (2007) Research methods in education, 6th edition. Routledge, London

Ellström PE (1992) Kompetens, utbildning och lärande i arbetslivet : problem, begrepp och teoretiska perspektiv, 1st edition. Publica : Allmänna förl, Stockholm. distributör

Ellström PE (1996) Arbete och lärande : förutsättningar och hinder för lärande i dagligt arbete. Arbetslivsinstitutet, Solna

Engeström Y (1987) Learning by expanding: an activity-theoretical approach to developmental research. Orienta-konsultit, Helsinki

Haglund B (2003) Stimulated recall. Pedagogisk Forskning i Sverige 8(3):145-157

Kvale S, Brinkmann S (2009) Den kvalitativa forskningsintervjun [Elektronisk resurs]. TPB, Enskede

Leontiev AN (1978) Activity, consciousness, and personality. Prentice-Hall, Englewood Cliffs, NJ

Lpf (1994) The 1994 curriculum for the non-compulsory school system (Lpf 94) [Elektronisk resurs]. Swedish Ministry of Education and Science, Utbildningsdep, Stockholm 
Merriam SB (1988) Case study research in education: a qualitative approach. Jossey-Bass, San Francisco, Calif SOU (1970:58) Yrkesutbildning och arbetsliv : samverkan och ansvarsfördelning : sammandrag av

Yrkesutbildningsberedningens (YB) betänkande VIII. Arbetsmarknadens yrkesråd, Stockholm

SOU (2001:78) Validering av vuxnas kunskap och kompetens [Elektronisk resurs]: slutbetänkande. Fritzes offentliga publikationer, Stockholm

Valsiner J (2000) Culture and human development: an introduction. SAGE, Thousand Oaks, Calif Vetenskapsrådet (2011) Resultatdialog 2011. Vetenskapsrådet, Stockholm

Vygotskij LS (1978) Mind in society: the development of higher psychological processes. Harvard U.P, Cambridge, Mass

Winther E, Achtenhagen F (2009) Measurement of vocational competencies. A contribution to an international

large-scale assessment on vocational education and training. Empirical Res Voc Educ Train 1(2009):85-102

Wolfinger NH (2002) On writing file notes: collection strategies and background expectancies. Qual Res 2(1):85-95

doi:10.1186/1877-6345-6-2

Cite this article as: Fjellström: Vocational education in practice: a study of work-based learning in a construction programme at a Swedish upper secondary school. Empirical Research in Vocational Education and Training 2014 6:2.

Submit your manuscript to a SpringerOpen ${ }^{\odot}$ journal and benefit from:

- Convenient online submission

Rigorous peer review

- Immediate publication on acceptance

- Open access: articles freely available online

- High visibility within the field

- Retaining the copyright to your article

Submit your next manuscript at $>$ springeropen.com 